\title{
The Ethics and Ontology of Synthetic Biology: a Neo-Aristotelian Perspective
}

\author{
Lewis Coyne $\mathbb{B}$
}

Received: 2 October 2018 / Accepted: 1 August 2019/Published online: 15 August 2019

(C) The Author(s) 2019

\begin{abstract}
This article is concerned with two interrelated questions: what, if anything, distinguishes synthetic from natural organisms, and to what extent, if any, creating the former is of moral significance. These are ontological and ethical questions, respectively. As the title indicates, I address both from a broadly neo-Aristotelian perspective, i.e. a teleological philosophy of life and virtue ethics. For brevity's sake, I shall not argue for either philosophical position at length, but instead hope to demonstrate their legitimacy through their explanatory power. I firstly argue that synthetic organisms differ in kind from natural organisms and machines, and differ only by degree from genetically modified organisms. I then suggest that this is nevertheless sufficient to give us specific ethical reservations about synthetic biology: namely, that more than any other widely used biotechnology, it is characterised by a drive to mastery that stands opposed to due appreciation of the giftedness of life.
\end{abstract}

Keywords Synthetic biology · Virtue ethics · Aristotle . Teleology $\cdot$ Philosophy of technology $\cdot$ Hans Jonas

L. Coyne $(\bowtie)$

Department of Sociology, Philosophy and Anthropology, University of Exeter, Amory Building, Rennes Drive, Exeter EX4 4RJ, UK

e-mail: 1c453@exeter.ac.uk

\section{The Bifurcation of Nature}

Synthetic biologists seek, broadly speaking, to create novel organisms using standardised biological parts and in accordance with engineering principles. The present analysis of synthetic biology will begin with the ontological question of what kind of beings synthetic organisms are, arriving at an answer by drawing comparisons with machines, natural organisms (henceforth 'organisms'), and genetically modified organisms (GMOs). First of all, therefore, we must define these entities, so as to clearly distinguish between them.

To some this might seem unnecessary. In fact it is anything but: not only do biologists and philosophers of science frequently describe organisms in mechanistic terms for heuristic purposes (which we might excuse), but many also go further and suggest that organisms actually are a kind of machine [1]. This ontological claim is, I believe, wholly erroneous and serves to undermine ethical analysis concerning both human and non-human life.

This misconception has a long and distinguished philosophical pedigree, however, stretching back at least as far as Descartes. Dividing the cosmos into res extensa and res cogitans, or 'extended' and 'intelligent' substances [2], Descartes' ontology promoted a theoretical 'bifurcation of nature' [3]. ${ }^{1}$ The former substance, res

\footnotetext{
${ }^{1}$ Of course, the orthodox Christianity of the Middle Ages also promoted a dualistic philosophy of nature insofar as it held humans, alone amongst terrestrial beings, to possess souls (the teachings of St. Francis being a notable exception to this doctrine). Nevertheless, Descartes' ontology is emblematic of modern ontology in this regard, both for its philosophical rigour and intended compatibility with modern science and mathematics.
} 
extensa, was the world of matter described by the physical sciences, while the latter, res cogitans, was the thinking subject of humanistic enquiry. As is well known, Cartesian substance dualism led to a conundrum in that the mind's apparent inseparability from the body could not be accounted for. To his credit, Descartes recognised that their relation was not simply like that of 'a pilot in his ship', but rather that the mind was 'joined and united more closely with the body' [2]. However, his notorious solution - that the point of connection was the pineal gland in the brain [4] - merely invited the response: how, then, was the mind joined to the pineal gland? No adequate answer conceived of on dualistic terms was forthcoming.

In spite of this fundamental flaw, Descartes' ontology has exerted a profound and lasting influence on Western thought. Our understanding of nonhuman life, in particular, still broadly aligns with his own. Recall that according to Descartes, only human beings were purposeful, courtesy of their subjectivity: the activity of animals and plants could be explained in mechanistic terms [4]; no reference to purposes, mental or organismic, was deemed necessary. Contemporary biologists and philosophers who regard organisms as machines simply follow suitthe only difference being that the industrial metaphors of pumps and pistons once used to describe them have now been replaced by computational ones of hardwiring and programming.

This mechanistic conception is lent credence by those who argue that understanding the world in terms borrowed from contemporary technologies is not only acceptable, but in fact inescapable - a claim that needs to be briefly addressed. Don Ihde, for instance, offers phenomenological descriptions of the role played by technology in experientially mediating between the self and the world, which he refers to as "the intentional arc [of] Human-instrument-World' [5]. He suggests that the medium of technology alters our experience of the world in two connected ways: 'embodiment relations' and 'hermeneutic relations' [5]. The former refers to the way in which technology can amplify or diminish our experience of aspects of the world. A magnifying glass, for example, intensifies our visual perception of whatever we put before it, while clothes diminish our perception of the surrounding air temperature. This is all straightforward enough. But Ihde argues that with the arrival of vastly more complex technologies, the reduction-amplification scale tips over into a novel hermeneutic capacity. Modern technology allows us to experience that which is otherwise invisible: atoms and subatomic particles, genes, distant galaxies, and so on [5]. The consequence of these two effects, Ihde claims, is that 'technology supplies the dominant basis for an understanding both of the world and ourselves' [6]. As such, those who conceive of organisms as machines are simply and unproblematically drawing on a normal facet of human experience.

This picture is no doubt correct, up to a point: technology does influence our perception in the ways Ihde suggests. The problem with his theory is that it gives up too soon, simply accepting the role played by technology in our understanding of the world. On the contrary, the fact that we frequently conceive of the natural world in technological terms does not mean that we have to or ought to, and indeed, that it is not always appropriate to do so is perfectly demonstrated by the inadequacy of the mechanistic conception of the organism. While organisms and machines share a likeness insofar as they can only be understood teleologically — or so I shall arguethe kinds of teleology belonging to each are very different. Acknowledgement of this difference is necessary for a full ontological analysis of synthetic organisms.

Aristotle remains the touchstone for any such account of the organism. Some readers will no doubt object to favourable references to Aristotle's biology, noting, for example, that his understanding of species as 'eternal' [7] has been discredited by Darwinism and the expansion of the fossil record. On this specific point they would be correct. But when Bernard Williams concludes, in this vein, that the "first and hardest lesson of Darwinism' is that 'that there is no such teleology at all' [8], we must not conflate - as so many philosophers do- the specific rejection of species essentialism with one of natural teleology in all its forms. ${ }^{2}$ The disavowal of all natural teleology is, by contrast, simply a methodological presupposition of the modern sciences, which should not be confused with a finding [9]. Other dimensions of Aristotle's conceptualisation of natural teleology remain a legitimate - indeed, an indispensable — philosophical resource.

\footnotetext{
${ }^{2}$ It does not seem from the context that Williams himself makes this mistake.
} 


\section{(Synthetic) Organisms and Machines}

Aristotle famously held that the existence of a thing could be attributed to four causes. Modern science implicitly operates according to (at most) three of these - the formal, material, and efficient - while overlooking the fourth or 'final' cause: the telos, 'for the sake of which a thing is done' [10]. As stated, there are two different kinds of teloi, which we may call immanent and transcendent. An artefact or machine's telos is always and entirely transcendent. As the term is used here, 'transcendent' does not refer to a divine entity or higher power, but simply means that the origin of the telos in question is separate from the being that instantiates it. In the case of a machine or other artefact this origin will, of course, be the person who designed it. ${ }^{3}$ A chair, for example, is teleologicalhaving been designed for sitting on - but there is a clear logical distinction between the chair having a telos and the origin of that telos, which transcends the chair itself.

The telos of an organism is quite different, both belonging to the thing itself and originating in it: hence 'immanent'. This kind of telos, according to Aristotle, pertains both to the 'natural organized body' [12] and its being 'moved by intellect, imagination, purpose, wish, and appetite' [13]. Clearly not all of the latter features are true of every living being — plants surely cannot 'wish' — but basic non-conscious purposes are nevertheless identifiable across the living world. ${ }^{4}$ Teleology understood in this twofold sense has inspired a variety of accounts of organismic being, including some that are themselves of enduring significance [16-18]. Perhaps the most penetrating such theory, however, is that of Hans Jonas. ${ }^{5}$ For both its

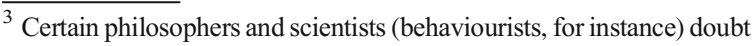
that humans act teleologically in a way that is irreducible to mechanistic explanation, contravening the idea that we could create beings according to purposeful designs. I follow Jonas in rejecting this view for phenomenological reasons [11], but of course concede that those who do not share this perspective will find my account of transcendent and immanent teleology suspect- thus undermining the general acceptability of the arguments set out here. Such is the nature of philosophically swimming against the stream.

${ }^{4}$ Even though plants cannot wish, they may, however, be able to communicate in a rudimentary fashion, indicating greater intelligence than has historically been attributed to them $[14,15]$.

5 Jonas has been deeply influential on Maturana and Varela's theory of autopoiesis and continues to feature both positively and negatively in related debates [19-23]. I avoid using the term, however, as its etymology suggests that a pre-existing organismic self acts as the author of its own phenotypic development. The reality is that, lacking any preexisting author, the organismic self is entirely brought into being in the act of phenotypic development, for which the term praxis might be more fitting. I thank Jack Griffiths for bringing this to my attention.
}

merits and its neo-Aristotelian character, I will refer to Jonas' work throughout the remainder of the essay. ${ }^{6}$

\section{An Ontological Analytic of the Organism}

From Aristotle Jonas takes up the notion of a twofold 'immanent teleology' [25], likewise locating it in the 'structure and behavior of the organism' [9]. These I call 'self-organisation' and 'purposive behaviour', so as to better capture their non-mechanistic flavour. We shall take each facet in turn, drawing comparisons with the teloi belonging to machines, before attempting on this basis to categorise synthetic organisms.

As stated, the first type of immanent teleology is the organism's self-organisation. Jonas' analysis of this phenomenon begins with metabolism. In it the organism achieves an 'independence of form with respect to its own matter' [9], as the organism actively maintains a formal identity through the act of absorbing and excreting substance. This immediately marks out a living being from, say, a stone, the form of which is at all times identical with its stable material composition. It even distinguishes an organism from a non-living being that is permanently in flux, such as a river or a fire: even though these entities undergo a constant material turnover - ceasing to be rivers or fires should they no longer do so - this exchange is not in the service of a persisting form, but merely one that is again reducible to material composition. Hence, as Heraclitus said, one cannot step into the same river twice.

Indeed, such is the uniqueness of metabolic being that Jonas suggests we may go further, and say that material composition is in fact of secondary import to the organism. Instead the organism principally exists as metabolic self-organisation:

In the process of its being, the parts of which the organism consists at a given instant are only temporary, transient contents whose joint material identity does not coincide with the identity of the whole which they enter and leave and which sustains its own identity by the very act of passage of

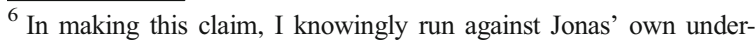
standing of his work. He claimed that 'Aristotle did not play much of a role' in his thinking, and was bemused that so many people should feel otherwise: 'there was little I could do to keep myself from being classified as a neo-Aristotelian. I would not have classified myself that way, but it's hard to defend yourself against others' views. At any rate, I wasn't in bad company' [24].
} 
foreign matter through its spatial system, the organic form. This whole is never the same materially and yet it persists as its same self - by not remaining the same matter [25].

Jonas stresses the uniqueness of organismic being in the universe by characterising the living thing's identity as a 'performance', 'act', and 'process rather than structure' [25]. ${ }^{7}$ Ontologically speaking, the organism is because it does, which must not be confused with a being whose 'is' is distinct from the fact that it does things. The entrance of this mode of being on the cosmological stage therefore allows us to speak of life as an 'ontological revolution' [9]. ${ }^{8}$

Now, the form achieved through metabolism is systemic, each component part deriving its identity from its place in the whole [30]. This applies both to individual cells and to organs, "which have come into existence through acts of self-articulation of the whole and are thus creations of that which they subserve' [25]. The radicalism of this thesis deserves to be spelled out. An organ is not, as its etymology implies, a tool or an instrument, which are extraneous beings that can always be picked up and set down by their user. The organ is instead part of the organism, clearly, but also a 'part of' it in a particular way. An unstructured being - a pile of rubbish, say-simply is the sum of its parts, as these could lie in any given way and the entity would remain the same. A house, by contrast, is a structure arranged in such-and-such a way, meaning that it is more than the sum of its parts. But still this 'more than' is something externally applied to the parts, which only take on their teleological status through an act of transcendent intent. The organism, however, as a process or act of selforganisation, is more than the sum of its parts andcrucially - also generative of them as parts.

The second form of immanent teleology exhibited by living beings is purposive behaviour [31]. 'Behaviour' is here employed in a broad sense, to mean an activity undertaken on the part of the organism in relation to

\footnotetext{
${ }^{7}$ Cf. Whitehead [26]. In his Memoirs, Jonas refers to Whitehead as a 'mighty figure' and concedes a profound debt to the latter [24]. For a comparative account of the two, see Donnelley [27], and for a more recent discussion of Jonas in relation to process philosophy, see Nicholson [28].

${ }^{8}$ This is not to say that Jonas adopts a new kind of substance dualism between living and non-living being. On the contrary, his 'integral monism' [9] holds that 'right from the beginning matter is subjectivity in its latent form, even if aeons, plus exceptional luck, are required for the actualizing of this potential' [29].
}

itself or its surroundings. Obvious examples are the acquisition of nutrition, the pursuit of sexual reproduction, and the avoidance of predators. Less obviously, at the micro-organismic level, living beings possess an irritability that is sensitive to certain stimuli. Common to all is the basic capacity of an organism to orient itself in its environment by relating to beings therein. In this way, the organism is, initially and for the most part, engaged with such beings in an instrumental fashion, as something-for nutrition, something-for traversing, something-for shelter, and so on. ${ }^{9}$ In each case, this 'something-for' indicates that organisms are beings 'whose being is committed to their own care' [25].

Jonas argues that purposive behaviour could only belong to a being that self-organises. Why? Because in the process of self-organisation, the organism wrests itself from the remainder of the world, putting matter at the service of its distinct formal identity. In this act of individuation, a boundary is created that governs the distinction between 'inside' and 'outside'. On the inside, the organism enjoys a freedom of form from matter, as we have seen, yet its dependence on outside beings for the acquisition of nutrition means that this is, paradoxically, a 'needful freedom' [9]. On the basis of this need, the organism then relates to the world from which it has separated itself:

In the single encounters this otherness has the quality of foreign body or influence which is either useful or harmful; in its entirety and as an enveloping horizon it has the character of 'the external world' confronting the organism's overwhelming concern in its own life-process which has to assert itself within it and, so committed, is of constitutive egoism. [25].

Thus, purposive behaviour is tied to the demands of organismic being and primarily oriented toward staving-off inexistence, regardless of the complexity of the living being in question.

\section{Machine-Being and Synthetic Organisms}

How, then, does this existence compare with that of a machine? It might be supposed that even though inert

\footnotetext{
${ }^{9}$ For this capacity, and with specific reference to animals, see Uexküll [32] and Heidegger [33]. It is Jonas' successful application of the notion of world-openness to life per se that marks him out from his forebears.
} 
artefacts and simple machines do not act in the organismic fashion outlined, modern technologies certainly do. We could think, first of all, of a car, the parts of which need petrol, oil, and water, amongst other things, for it to run properly and not break down. Is this not a systematic entity identical to the organism, which equally requires sustenance in order to continue living?

In fact there is only a superficial similarity between the relations of car to fuel and organism to sustenance. This becomes apparent when noting that the car utilises fuel without the fuel ever becoming the car, whereas metabolism entails that the organism actually reconstitutes itself [34]. This is, to reiterate, the organismic condition: for as long as the organism lives it is irreducible to its material composition, only becoming the latter when it ceases to metabolise-i.e. die. ${ }^{10}$ A machine, on the other hand, has a material identity that is complete whether switched on or off, because the formal division between itself and the world is not its own doing.

This key difference then serves to explain the difference between organisms and yet more complex machines that appear to purposefully behave in relation to their surroundings. Robots are the most obvious example, but even the humble thermostat is, through feedback loops, able to take cues from its environment and then regulate its own functioning so as to modify that selfsame environment. Would we be right to say that the atmosphere surrounding the thermostat is something there for the thermostat to engage with, indicating purposeful behaviour on the part of the machine? Surely we would not: this is teleological functioning, no doubt, but again of a different kind compared with that of the organism. Whatever is of relevance to the thermostat in the external world is not based on any kind of need, grounded in processual being, but merely represents an input into a fixed and self-sufficient system. And the reason for this self-sufficiency harks back to the nature of the machine, which is an arrangement of matter in accordance with a telos that transcends it.

Having staked out the basic ontological difference between organisms and machines, we may now turn to synthetic organisms. A clue as to their ontological status may be found in the preceding paragraph. We said that - in contrast to the immanent telos of an organism - the principle of a machine is an arrangement

\footnotetext{
${ }^{10}$ Perhaps the closest exceptions are the dormant state of a seed, during which it still respires, and the capacity of micro-organisms to conduct minimal metabolic activity when frozen, sometimes for millennia.
}

of matter in accordance with a telos that transcends it. Which, then, is true of a synthetic organism? Is its telos transcendent or immanent? Is it an organism or a machine?

Unfortunately there is no straightforward answer to this question. Although, as Jan Schmidt notes, the defining characteristic of synthetic biology is that it 'harnesses, or aims to harness, the self-organization power of nature' [35], the discipline is comprised of a multitude of techniques that have differing implications for our present enquiry. Simplifying matters greatly, however, we can divide these techniques into two kinds. 'Top-down' methods typically insert selected genetic material into pre-existing cells stripped of their nuclei, whereas 'bottom-up' methods seek to build artificial cells in toto from rudimentary biological materials such as proteins. The former is synthetic biology as it is currently practiced, while the latter is a research effort that is not yet technologically feasible [36].

This division of techniques undermines analyses of synthetic biology that stress its radical novelty. For instance, Christopher Preston [37] has argued that synthetic biology represents a break even from previous biotechnologies, as it now allows for the wholesale substitution of the natural with the artificial. But as Tim Lewens [38] notes, the science as a whole cannot be described as such - rather, its two different forms permit varying degrees of substitution of the natural by the artificial. The ontological status of synthetic organisms is therefore dependent, to some extent, on the method of synthetic biology employed.

Taking top-down synthetic biology first, the answer lies somewhere in between our previously drawn distinctions: a synthetic organism created in this way has characteristics of both an organism and a machine [39], being teleological partly in the immanent sense and partly in the transcendent sense. If this sounds odd, in light of the starkly distinguished account of immanent and transcendent teleology given above, then we would note that a substantial amount of non-human life already possesses this status. Animals bred by humans are one example, GMOs another. Put in the language used so far, we may say that while such an organism organises itself and behaves purposefully, the way it carries out both capacities are to varying degrees subject to the design of an external agent: namely, the farmers who selected the organism's ancestors or the scientists who modified its genome. And much the same is true, only more so, of a top-down synthetic organism, the parts of 
which are chosen to inform its development in fundamental ways. As such, this type of synthetic organism appears near the far end of a scale of living beings that are partly characterised by purposes transcendent of themselves.

Then there are bottom-up methods of synthetic biology. As stated, these are at present a research goal rather than a reality. If, however, such methods are viable, it seems plausible to say that this would represent the most transcendentally teleological living being yet produced, and perhaps that even could be produced. The reason is that its organisation and behaviour would be almost entirely subject to human design, a truly novel being built from standardised biological (or at least 'biologically active') parts. Note, however, that I say almost entirely subject to human design, as the components used would still be living. This reflects both their origin-derived from organisms that were selforganising - and, more importantly, their potential. Precisely because the parts in question are living a synthetic organism created in this way would still be processual rather than merely mechanistic, likely possessing the organismic features of mutation, aging, and mortality. The first of these is perhaps the most interesting for the question at hand, as it suggests that were the synthetic organism able to reproduce it might eventually give rise to something other than that intended by its designer. And even if it did not reproduce, adaptive plasticitywhich we shall address below-means that such an organism might deviate from its transcendent telos even within its own lifetime.

Now, some philosophers have attempted to collapse the ontological distinctions between synthetic organisms, machines, and natural organisms by shifting the analytic focus toward evolution. They argue that, just like a machine, the development of an organism is always subject to the design of an external being: in this case, evolution by natural selection. On this view, a machine's telos has a self-conscious transcendent source in its designer, to be sure, but the organism's telos, being the result of natural selection, is fundamentally the same-simply unconsciously designed. And, since synthetic organisms share characteristics of both organisms and machines, the same must be true of these by extension.

This is precisely the argument made by John Basl and Ronald Sandler. Living things are 'genuinely goaldirected systems because the parts and processes of the organism were selected for in their ancestors and thereby exist in the organisms for the purpose of realizing certain ends' [40]. This also holds for synthetic organisms, which 'have parts and processes selected for because they contribute to certain goals', as well as for the creation of artefacts: '[ $t$ ] he parts and processes of (almost all) traditional artifacts have selection etiologies i.e., they were selected for by humans because they had certain consequences relevant to achieving our ends' [40]. Thus, all are ultimately the same insofar as their telo $i$ are transcendent in origin, regardless of whether the designer in question is a person or natural selection.

Although we shall turn to axiology in the next section, it is worth mentioning that Basl and Sandler's line of reasoning leads them to the curious conclusion that 'artefacts have a good of their own' [40] distinct from those of their designers. Something has clearly gone wrong here, which we can elucidate with reference to the fundamental distinction between immanent and transcendent teleology. According to Larry Wright's classic etiological account of biological functions [41], which Basl and Sandler draw upon, evolution by natural selection acts like a designer of artefacts. This in turn implies that the organism is a passive bystander in evolutionary history and its own ontogeny, just like the artefact that has no influence over its design and production. For both reasons, it would seem that Basl and Sandler ultimately conceive of the organism as teleological in the transcendent sense alone. But are they right to?

When we critically examine the parallels drawn between evolution and a designer and the organism and an artefact, we see that neither stands up to scrutiny. To take the latter first, organisms are not, in fact, passive with regard to their phenotypic development and therefore the evolutionary history of their kind. As Lenny Moss notes, genetic sequences do not determine phenotypes, but are rather 'indeterminate resources deployed by the developing organisms in different ways, in different places, [and] at different times' [42]. In other words, phenotypic development-including not only the organism's learned behaviour but also its very physiological functioning - is subject to environmental influence. True, this 'adaptive plasticity', as it is called, by itself indicates only a certain reactiveness on the part of the organism. It is crucial to note, therefore, that the organism can also make changes to its environment - known as 'niche construction'-which then feed back into the process of adaptive plasticity [43]. The upshot is that even over the course of a lifetime, the organism can unintentionally alter its own development, which of course then feeds into the evolutionary process if it 
should reproduce. For this reason, Basl and Sandler are wrong to treat living beings as teleologically analogous to artefacts.

The second, decisive problem is that the etiological account works by drawing a parallel between the evolutionary process and a designing agent. Understanding evolution in this way is perfectly acceptable in a theological setting, where it can be taken to mean that evolution occurs according to a divine intent. But Basl and Sandler are of course speaking in strictly secular philosophical and scientific terms. In that case, the parallel being drawn is between an agent who has purposes and can design beings in accordance with them, and the blind operations of natural selection. But the very idea of 'design without a designer', which is intended to work in this context, ultimately misrepresents natural selection, as Daniel Nicholson notes:

The adaptations produced by evolution are not the result of an intentional preconceived plan by an external agent, but are rather the consequence of the differential survival and reproduction of organisms with heritable adaptive variations. It would be far more appropriate to assert that organisms are 'fashioned' or 'shaped' by selection pressures than to invoke design as an explanatory concept [44].

Full recognition of the fact that evolution is no intentional or agential force means we cannot speak of organisms as designed in any sense. The organism is instead an active participant in its own development and an agent in evolutionary history, responding to various pressures and succumbing to others. And with the collapse of the parallels Basl and Sandler drew between evolution and a designer and an organism and an artefact, synthetic organisms can indeed occupy the space in between the latter pairing, as I have suggested.

\section{The Axiological Dimension of Teleology}

Before turning to the next section of this article, which concerns the ethics of creating synthetic organisms, the axiological implications of our ontological investigation will be drawn out. This is with a view to the ethical analysis that follows, insofar as knowing what kinds of value synthetic organisms possess conceivably allows us to better judge the ethics of synthetic biology.
The axiological distinction that most neatly maps onto that of immanent and transcendent teleology is intrinsic and instrumental value. Although these terms have been defined in a multitude of ways, I take them to mean the following, based on a threefold distinction offered by Holmes Rolston III. ${ }^{11}$ Instrumental value refers to something's capacity to act as a means to an end posited by the valuer. This is logically distinct from extrinsic value, which we find in something without reference to instrumental needs. 'Tourists in Yosemite', for instance, 'do not value the sequoias as timber but as natural classics, for their age, strength, beauty, resilience and majesty' [49]. This much is clear. Perhaps more controversially, Rolston suggests that intrinsic value belongs to valuers themselves, those beings capable of valuing: in Rolston's word play, they are quite literally 'value-able, able to produce values' [49]. Such entities have intrinsic value as the valuing itself comes from within. ${ }^{12}$

What kinds of value belong to synthetic organismsinstrumental, extrinsic, or intrinsic? It seems that almost anything can have instrumental or extrinsic value, since these simply depend upon the purposes and perspective of a valuing agent. Even some waste materials can be put to use (as fertiliser, for example), and so be said to have instrumental value, or viewed for any aesthetic merit, perhaps, and thus have extrinsic value. There seems to be no reason why these kinds of values cannot also be found in synthetic organisms; indeed, the fact that they possess the former is their very raison d'etre. But do they also possess intrinsic value? Are they, in other words, capable of valuing?

The specific question of whether synthetic organisms can value extrinsically will be set aside, since this was defined as a non-instrumental valuing, which complicates matters somewhat. ${ }^{13}$ The more elementary is surely instrumental valuing, the capacity for which, according to the terms we have adopted, is sufficient for an

\footnotetext{
${ }^{11}$ John O’Neill [45], in particular, has provided a subtle analysis of the manifold senses of intrinsic value, but for the purposes of this article, the definitions given will suffice. The scope and meaning of the term 'intrinsic value' was a foundational debate in environmental ethics [46-48].

12 This says nothing, however, about the moral worth, considerability, or relative significance of such beings, which are logically distinct issues.

${ }^{13}$ Rolston argues that there is one way in which all organisms value extrinsically, namely, their striving for continued existence: '[a] life is defended for what it is in itself, without necessary further contributory reference' [49]. Jonas concurs, suggesting that the fact that the organism maintains itself in being simply for itself means that this existence is valued 'beyond all instrumentality' [29].
} 
entity to have intrinsic value. To ascertain whether synthetic organisms can value in this way, a comparison with organisms and machines is once again in order.

We said above that organisms have immanently teleological ends in their self-organisation and purposeful behaviour, the latter principally manifesting in the pursuit of continued existence. As a result, certain entities in the world enable an organism to fulfil these goals (appropriate nutrition, for example), while others hinder it (such as poisons or predators). The axiological consequence is this: each organism possesses a subjective good and bad as a matter of logical necessity, since something can be better or worse for it according to the satisfaction or otherwise of its ends. As Jonas remarks, with 'any de facto pursued end [...] attainment of it becomes a good, and frustration of it, an evil; and with this distinction the attributability of value begins' [50]. What kind of value does Jonas have in mind? The answer is surely instrumental value, since we are referring to the capacity of entities to either impede or act as means to the organism's ends. Note that this valuing does not have to involve an affective or cognitive dimension, ${ }^{14}$ although in much animal and human life it no doubt does. On the contrary, such valuing simply follows as a matter of course from the immanent teleology belonging to living beings.

What, then, of machines, which in contrast to organisms function (or fail to function) according to transcendent teloi imparted by their designers? Here matters are quite different. Because the telos of a machine is entirely imposed from without, meaning there is no basis in necessity for purposeful behaviour, the ends of the machine cannot really be called its own. Following form this lack is the incapacity to value, since without even the minimal goal of continued existence nothing can be better or worse for the machine itself, only better or worse for its designer or user.

Employing slightly different terminologies and examples, this is nevertheless a point well made by Paul Taylor:

Suppose [...] that someone tells us that we can further the good of a pile of sand by, say, erecting a shelter over it so that it does not get wet in the rain. [...] Perhaps we would interpret the statement to mean that, since wet sand is no good for a certain purpose, it should be kept dry. In that case it is not the sand's own good that would be furthered, but

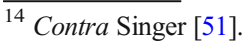

the purpose for which it is to be used. [...] Concerning the pile of sand itself, however, it is neither true nor false that keeping it dry furthers its good. The sand has no good of its own [47].

Much like Taylor's pile of sand, the machine lacks the necessary immanent teleology for instrumental (and $a$ fortiori extrinsic) valuing and thereby cannot be said to have intrinsic value. It is for this reason that Basl and Sandler are wrong about the axiological status of artefacts: the only value a machine has is that which we find in it.

Now we may turn again to synthetic organisms. We saw in the previous section that their ontological status was ambiguous, characterised by teloi that are immanent and transcendent. This would in turn suggest an ambiguous axiological status, for the attribution of intrinsic valuing rested on the presence of immanent, and not transcendent, teleology.

It may be, however, that having a partly immanent telos is enough. While a synthetic organism exists qua organism because of us, once created it nevertheless exists for itself (even if this is in ways that we have largely specified, or, in the case of bottom-up synthetic organisms, almost entirely specified). Clearly, a synthetic organism carries out particular functions because we made it that way. But as a metabolising being, it would still exhibit purposeful behaviour in striving to continue in existence, meaning that it has 'proximate' interests of its own even if its 'ultimate' interests are defined by the synthetic biologist [52]. ${ }^{15}$ As before this is also true, albeit to a far lesser extent, of GMOs and animals or plants bred by humans. Since there is no reason to doubt that these beings are capable of instrumental valuing via their proximate interests, thereby possessing the status of intrinsic value, the same is true of synthetic organisms. It seems, then, that what matters for the identification of intrinsic value is not whether a being is natural or humanly designed, but simply that it is alive.

\section{The Drive to Mastery and Giftedness of Life}

Having staked out the ontological and axiological terrain occupied by synthetic organisms, we are now in a better position to ethically assess their creation. As

\footnotetext{
$\overline{15}$ The exception to this would be a synthetic organism whose ultimate interests were in conflict with and overrode its proximate ones, such as an organism designed to simply die [52].
} 
stated, I will not broach this issue from a consequentialist or deontological perspective, but rather - continuing our Aristotelian theme - that of virtue ethics, which of course has its roots in the Nicomachean Ethics [53] and Politics [54]. ${ }^{16}$ The question motivating the remainder of this essay, therefore, is whether synthetic biology is a practice that is generally conducive to the good life and good society. I suggest that it is not, embodying as it does an attitude of intense mastery that stands opposed to due appreciation of the giftedness of life.

I here take inspiration from Michael Sandel, who has argued for these reasons against human enhancement. Although concerning a different kind of biotechnology put to different ends, it is worth quoting the pivotal section of Sandel's essay at length:

The deeper danger is that they [human enhancement and genetic engineering] represent a kind of hyperagency, a Promethean aspiration to remake nature, including human nature, to serve our purposes and satisfy our desires. The problem is not the drift to mechanism but the drive to mastery. And what the drive to mastery misses, and may even destroy, is an appreciation of the gifted character of human powers and achievements. To acknowledge the giftedness of life is to recognize that our talents and powers are not wholly our own doing [...]. It is also to recognize that not everything in the world is open to any use we may desire or devise. An appreciation of the giftedness of life constrains the Promethean project and conduces to a certain humility [56].

The above rests on two notions that are contentious enough to require justification. Even if an attitude of mastery is readily understood, as I take it to be, what does it mean for an action or practice to represent it? And what, exactly, is the 'giftedness' of life, appreciation of which stands to be destroyed?

Reflecting broader misunderstandings of Sandel, treatment of these issues in the context of synthetic biology has thus far been inadequate. Thomas Douglas, Russell Powell, and Julian Savulescu have briefly

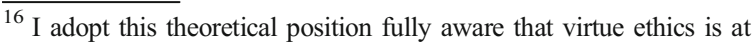
odds with mainstream Anglo-Saxon bioethics, which tends to favour a blend of consequentialism and deontology. In part this simply reflects the commitments of Anglophone philosophers, but it is also, more defensibly, due to the fact that virtue ethics does not readily lend itself to policy recommendations. As an illustration of the latter point in relation to synthetic biology, see Gutman [55].
}

discussed how synthetic biology might express attitudes, while Lewens has considered the value of lifeyet all fail to address precisely what Sandel means and consequently disregard his argument too readily. I shall attempt to make sense of Sandel's argument and show that it does, in fact, constitute a valid virtue ethical objection to synthetic biology.

The first problem is how an action or practice can represent an attitude. Douglas et al. claim that 'what attitudes the production of an organism expresses plausibly depends on what attitudes the creator of that organism actually has', or, more broadly, on the attitudes 'typically associated' with synthetic biologists [57]. This undoubtedly matters, morally speaking, as it reflects upon the character of the individuals involved. Yet Sandel's claim is not about the expression, but rather the representation of attitudes by our actions and the practices we engage in. The crucial difference is that the latter can be entirely divorced from the attitudes a practitioner subjectively has. Thus, I take Sandel to mean not that an attitude of mastery belonging to genetic engineers is communicated through the practice: some genetic engineers might not have this attitude, and some may even positively respect, up to a point, the object of their engineering efforts. If so, this much is commendable. Sandel's point, however, is rather that the practice of genetic engineering is a form or manifestation of the drive to mastery, granting as it does the power to refashion living beings according to our desires. When we engage in genetic engineering, our actions are in accordance with this end, regardless of whether this is what consciously motivates us.

Lewens makes a similar mistake when drawing on examples from scientific and agricultural history. We need not have specific concerns about synthetic biology, he suggests, because 'the aspiration to modularized, rational control over the design of artificial organisms, one of the defining themes of synthetic biology, was already present in the earliest years of genetics' [38]. Of course, hardly anyone would regard the breeding of plants and animals as ethically suspect, and so it should follow that we ought to extend the same tolerance to modern synthetic biologists.

Again, however, this does not observe the distinction between the attitudes of the scientists in question and the characteristics of their actions. Consider, for instance, that the desire for the rational design of organisms actually long predates any kind of breeding programme informed by genetics. Four centuries ago, Francis Bacon 
wrote insightfully of modern science's technological potential, and in his utopian tale The New Atlantis even envisages scientists who are able to make novel organisms from simple parts and according to rational principles:

We make a number of kinds, of serpents, worms, flies, fishes, [out] of putrefaction, whereof some are advanced (in effect) to be perfect creatures, like beasts or birds, and have sexes, and do propagate. Neither do we do this by chance, but we know beforehand of what matter and commixture, what kind of those creatures will arise [58].

Bacon's vision is much the same as those of the animal and plant breeders Lewens discusses, and uncannily like that of synthetic biologists today. But whether individuals subjectively aspire to mastery is just one factor - albeit a major one - in the ethical evaluation of their character. What also matters is the extent to which the practices they engage in embody the drive to mastery. This is the ethical difference between Bacon himself, who had no access to such technologies, and a contemporary synthetic biologist able to act upon the Baconian ideal.

This brings us back to the issue at hand. As we have seen, synthetic biology, more than any other widely deployed biotechnology or breeding programme, grants power over the development of living beings. Today this is true of top-down synthetic biology, which would itself be superseded by the development of bottom-up synthetic biology, should it prove viable. This gives us a prima facie reason for specific ethical reservations, as, regardless of whether synthetic biologists conceive of themselves in this way, by engaging in the practice they adhere to the drive to mastery in arguably its purest technological form yet. This in turn reflects both on their moral character, and, to the extent that the practice is supported by the general public, that of society at large.

So much for the first misunderstanding. The second pertains to the most contentious aspect of Sandel's argument, namely, the 'giftedness of life'. Sandel suggests that the drive to mastery stands opposed to acknowledgement of the giftedness of life, although what this latter notion refers to is not immediately clear. What is clear, however, is that Sandel does not mean 'mastery over the feeble efforts of Mother Nature', or 'some kind of Promethean assault on the "given" of the natural world', as Lewens suggests [38]. Although Sandel discusses the natural, the given, and the unbidden, the worth of these is dependent on their relation to the real object of his concern, namely, the gifted. ${ }^{17}$ This is no semantic quibble, but of the utmost importance.

I will briefly draw out the distinctions between these terms. 'Nature' is famously multifarious, but, in this context, would perhaps most readily be understood as referring to that which exists independently of human action and/or intent. The 'unbidden' is a somewhat broader notion, as it refers to anything, natural or otherwise, that comes into our purview without our intending it. Lastly, the 'given', though sharing a likeness to both of the above, is harder to define - at least in the 'transpersonal' rather than interpersonal sense Lewens invokes. For something to be given in the interpersonal sense, one simply has to hand it over to someone else. Transpersonal givenness, however, is more elusive, as here there is no giver at all. In this sense, the given refers to that which exists independently of one's actions and those of the people we live alongside. It encompasses the natural and the historical, the past surely being 'given' par excellence.

The gifted is none of these. To be sure, for something to be gifted it has to be given, either in the interpersonal or transpersonal sense. But it is different and more precious. The gifted is something that is given and ought to be appreciated as valuable. If it has a giver, then they must certainly intend that the gift enrich its recipient's life in some way, large or small. However, precisely because the given need not have a giver nor must the gifted. We can, and often do, think of our health, senses, abilities, and good fortune, or the beauty and sublimity of nature, as gifts, even though they were not given to us by anyone. ${ }^{18}$ Occasionally, we even think of a misfortune that has befallen us as a gift, such as an illness that allows us to newly or fully appreciate what we have. All are gifts from nowhere and no-one. And I would suggest that life, too, is such a gift: a wellspring of novelty, purpose, and intrinsic value in an otherwise desolate cosmos.

Sandel suggests that recognition of the giftedness of life allows us to live well because it 'conduces to a certain humility', but its meaning for the good life is arguably more fundamental. Michael Hauskeller-one of Sandel's few sympathetic interpreters - suggests that

\footnotetext{
${ }^{17}$ For an analysis of the ethics of synthetic biology and appreciation of 'the given', see Link [59].

${ }^{18}$ Unless, of course, one believes in a personal God.
} 
'appreciating the giftedness of life helps us feel at home in the world. It creates a bond, connects us to the rest of the world, which then no longer appears hostile and forbidding' [60]. By contrast, '[t]he drive to mastery and the denial of giftedness affirm this enmity. They reinforce an almost Manichaean point of view, according to which $[\ldots]$ the physical world is out there to be subjugated' [60]. It is for this reason that Sandel can credibly oppose the giftedness of life and the drive to mastery: the former allows us to feel at home in the living world and its wider cosmic setting, while the latter diminishes the sense of home by viewing these as mere means to our ends.

Does acknowledging the giftedness of life and constraining the drive to mastery then entail absolute asceticism? Ought we vow, like Jain monks, to injure no living being in thought or in action? Surely not. For virtue ethicists eudaimonia is achieved through a multiplicity of virtues, some of which entail — not in principle, but at least in practice - a degree of mastery over the gifted. But acknowledging the giftedness of life holds such mastery in check. It enables us to resist 'the ruling pragmatism of our time', which 'will let no ancient fear and trembling interfere with the relentless expanding of the realm of sheer thinghood and unrestricted utility' [61].

How in practice, then, should we balance any necessary mastery of life with the appreciation of its giftedness? On this point, virtue ethics is unspecific (or, in the eyes of its detractors, vague), as it holds circumstances to be paramount for judging the right course of action. In this spirit I would make the following observation. Societies as intensely instrumentalistic and economistic as our own do not need less recognition of the giftedness of life, but a great deal more. In addition to individually cultivating receptivity to it, we would benefit from collectively adopting certain practices and renouncing others. Synthetic biology would be a strong candidate for the latter camp. For the danger of synthetic biology is that it deeply embodies the attitude of mastery according to which life is a mere 'standing reserve of function' [62]. And as we have seen life is no such thing. Far from being mere artefacts or machines, living beings are selforganising, intrinsically valuable, and strive in their own way for continued existence. The emergence of life in the cosmos is, as Jonas said, an ontological revolution. To acknowledge and welcome this fact is to acknowledge the giftedness of life, and feel at home in the world.

\section{Conclusion}

The foregoing reflections are, of course, motivated by certain neo-Aristotelian convictions. Rejecting the dominant mechanistic paradigm in the philosophy of biology, I have attempted to show that immanent teleology distinguishes living beings from machines and other artefacts. This matters greatly for how we view synthetic organisms, as the mechanistic conception obscures the ontological space they occupy between organisms and machines. An adequate philosophy of life in turn has significance for an axiological analysis of synthetic organisms, as it suggests that not only do they have instrumental and extrinsic value for us - something they share with machines - but also intrinsic value, which living beings alone possess. And a virtue ethical perspective, placing the good life and good society centre stage, is able to account for the moral significance of the drive to mastery and recognition of the giftedness of life. Overall, this perspective reveals synthetic biology to be a prime candidate for collective renunciation.

Of course, not only do I take these neo-Aristotelian positions to have a greater degree of explanatory power than the alternatives, but I also assume that they have defensible foundations. Those who doubt the validity of a teleological view of life and eudaimonistic ethics, however, may not be persuaded otherwise by my attempt to bring these to bear on the topic of synthetic biology. This is perhaps most true of my suggestion that greater acknowledgment of the giftedness of life would conduce to our attaining the good life and good society. But in demonstration of this last claim, philosophy must ultimately give way to worldly experience.

Sweet is the lore which Nature brings;

Our meddling intellect

Mis-shapes the beauteous forms of things: -

We murder to dissect.

Enough of Science and of Art;

Close up those barren leaves;

Come forth, and bring with you a heart

That watches and receives. [63]

Acknowledgements I would like to thank Jack Griffiths and two anonymous reviewers for helpful comments on this essay, as well as Darian Meacham and Miguel Prado Casanova for inviting me to write it in the first place. 
Funding This work was supported by the Economic and Social Research Council of the United Kingdom (Studentship No: 1358712).

Open Access This article is distributed under the terms of the Creative Commons Attribution 4.0 International License (http:// creativecommons.org/licenses/by/4.0/), which permits unrestricted use, distribution, and reproduction in any medium, provided you give appropriate credit to the original author(s) and the source, provide a link to the Creative Commons license, and indicate if changes were made.

\section{References}

1. Nicholson DJ (2013) Organisms $\neq$ machines. Stud Hist Phil Biol Biomed Sci 44(4: part B):669-678. https://doi. org/10.1016/j.shpsc.2013.05.014

2. Descartes R (1968) Discourse on method and the meditations (trans: Sutcliffe FE). Penguin, London

3. Whitehead AN (1920) The concept of nature. Cambridge University Press, Cambridge

4. Descartes R (1972) Treatise of man (trans: Hall TS). Harvard University Press, Cambridge, MA

5. Ihde D (1979) Technics and praxis. D. Reidel, Dordrecht

6. Ihde D (1983) Existential technics. State University of New York Press, Albany

7. Aristotle (1984) Generation of animals. In: Barnes J (ed) Complete works, vol 1. Princeton University Press, Princeton, pp 1111-1218

8. Williams B (1995) Making sense of humanity. Cambridge University Press, Cambridge

9. Jonas H (1966) The phenomenon of life: toward a philosophical biology. Northwestern University Press, Illinois

10. Aristotle (1984) Physics. In: Barnes J (ed) Complete works, vol 1. Princeton University Press, Princeton, pp 315-446

11. Coyne L (2017) Phenomenology and teleology: Hans Jonas's philosophy of life. Environmental Values 26(3): 297-315

12. Aristotle (1984) De Anima. In: Barnes J (ed) Complete works, vol 1. Princeton University Press, Princeton, pp 641-692

13. Aristotle (1984) Movement of animals. In: Barnes J (ed) Complete works, vol 1. Princeton University Press, Princeton, pp 1087-1096

14. Karban R (2015) Plant sensing and communication. Chicago University Press, Chicago

15. Blande JD, Glinwood R (eds) (2016) Deciphering chemical language of plant communication. Springer, Cham

16. Goldstein K (1995) The organism: a holistic approach to biology derived from pathological data in man. Zone Books, New York

17. Canguilhem G (2008) Knowledge of life (trans: Geroulanos S, Ginsburg D). Fordham University Press, New York

18. Maturana HR, Varela FJ (1980) Autopoiesis and cognition: the realization of the living. D. Reidel, Dordrecht

19. Weber A, Varela FJ (2002) Life after Kant: natural purposes and the autopoietic foundations of biological individuality. Phenomenol Cogn Sci 1(2):97-125
20. Thompson E (2004) Life and mind: from autopoiesis to neurophenomenology. A tribute to Francisco Varela. Phenomenol Cogn Sci 3(4):381-398

21. di Paolo EA (2006) Autopoiesis, adaptivity, teleology, agency. Phenomenol Cogn Sci 4(4):429-452. https://doi. org/10.1007/s11097-005-9002-y

22. de Jesus P (2016) Autopoietic enactivism, phenomenology and the deep continuity between life and mind. Phenomenol Cogn Sci 15(2):265-289

23. Villalobos M, Ward D (2016) Lived experience and cognitive science: reappraising enactivism's Jonasian turn. Constructivist Foundations 11(2):204-212

24. Jonas H (2008) Memoirs (trans: Winston K). Brandeis University Press, Lebanon

25. Jonas H (2016) Organism and freedom: an essay in philosophical Biology (ed. by Beckers JO, Preußger F). Rombach, Freiburg im Breisgau

26. Whitehead AN (1978) Process and reality: an essay in cosmology, 2nd edn. The Free Press, New York

27. Donnelley S (1978) Whitehead and Jonas: on biological organisms and real individuals. In: Spicker SF (ed) Organism, medicine, and metaphysics: essays in honor of Hans Jonas on his 75th birthday. D. Reidel, Dordrecht

28. Nicholson DJ (2018) Reconceptualizing the organism: from complex machine to flowing stream. In: Nicholson DJ, Dupré J (eds) Everything flows: towards a processual philosophy of biology. Oxford University Press, Oxford, pp 139-166

29. Jonas H (1996) Mortality and morality: a search for the good after Auschwitz. Northwestern University Press, Illinois

30. Toepfer G (2012) Teleology and its constitutive role for biology as the science of organized systems in nature. Stud Hist Phil Biol Biomed Sci 43(1):113-119. https://doi. org/10.1016/j.shpsc.2011.05.010

31. Barham J (2012) Normativity, agency, and life. Stud Hist Phil Biol Biomed Sci 43(1):92-103. https://doi.org/10.1016 /j.shpsc.2011.05.008

32. von Uexküll J (2010) A foray into the worlds of animals and humans (trans: O'Neil JD). University of Minnesota Press, Minneapolis

33. Heidegger M (1995) The fundamental concepts of metaphysics: world, finitude, solitude (trans: McNeill W, Walker N). Indiana University Press, Bloomington

34. von Bertalanffy L (1952) Problems of life: an evaluation of modern biological and scientific thought. Harper \& Brothers, New York

35. Schmidt JC (2016) Prospective technology assessment of synthetic biology: fundamental and propaedeutic reflections in order to enable an early assessment. Sci Eng Ethics 22(4): 1151-1170. https://doi.org/10.1007/s11948-015-9673-x

36. Göpfrich K, Platzman I, Spatz JP (2018) Mastering complexity: towards bottom-up construction of multifunctional eukaryotic synthetic cells. Trends Biotechnol 36(9):938951. https://doi.org/10.1016/j.tibtech.2018.03.008

37. Preston CJ (2008) Synthetic biology: drawing a line in Darwin's sand. Environmental Values 17(1):23-39. https://doi.org/10.3197/096327108x271932

38. Lewens $\mathrm{T}$ (2015) The biological foundations of bioethics. Oxford University Press, Oxford 
39. Schark M (2012) Synthetic biology and the distinction between organisms and machines. Environmental Values 21(1):19-42

40. Basl J, Sandler R (2013) The good of non-sentient entities: organisms, artifacts, and synthetic biology. Stud Hist Phil Biol Biomed Sci 44(4: part B):697-705. https://doi. org/10.1016/j.shpsc.2013.05.017

41. Wright L (1976) Teleological explanations: an etiological analysis of goals and functions. University of California Press, Berkeley

42. Moss L (2005) Darwinism, dualism, and biological agency. In: Hösle V, Illies C (eds) Darwinism and philosophy. University of Notre Dame Press, Notre Dame, pp 349-363

43. Barker G (2015) Beyond biofatalism: human nature for an evolving world. Columbia University Press, New York

44. Nicholson DJ (2014) The machine conception of the organism in development and evolution: a critical analysis. Stud Hist Phil Biol Biomed Sci 48(Part B):162-174. https://doi. org/10.1016/j.shpsc.2014.08.003

45. O’Neill J (1992) The varieties of intrinsic value. Monist 75(2):119-137

46. Callicott JB (1984) Non-anthropocentric value theory and environmental ethics. Am Philos Q 21(4):299-309

47. Taylor PW (1986) Respect for nature: a theory of environmental ethics. Princeton University Press, Princeton

48. Attfield R (1987) Biocentrism, moral standing and significance. Philosophia 39(1):47-58

49. Rolston H III (1994) Value in nature and the nature of value. In: Attfield R, Belsey A (eds) Philosophy and the natural environment: Royal Institute of Philosophy Supplement 36, vol 36. Cambridge University Press, Cambridge, pp 13-30. https://doi.org/10.1017/s1358246100006421

50. Jonas H (1984) The imperative of responsibility: in search of an ethics for the technological age (trans: Jonas H, Herr D). Chicago University Press, Chicago

51. Singer P (1993) Practical ethics, 2nd edn. CUP, Cambridge

52. Deplazes-Zemp A (2012) The moral impact of synthesising living organisms: biocentric views on synthetic biology. Environmental Values 21(1):63-82
53. Aristotle (1984) Nicomachean ethics. In: Barnes J (ed) Complete works, vol 2. Princeton University Press, Princeton, pp 1729-1867

54. Aristotle (1984) Politics. In: Barnes J (ed) Complete works, vol 2. Princeton University Press, Princeton, pp 1986-2129

55. Gutman A (2011) The ethics of synthetic biology: guiding principles for emerging technologies. Hast Cent Rep 41(4): 17-22

56. Sandel MJ (2007) The case against perfection: ethics in the age of genetic engineering. Harvard University Press, Cambridge

57. Douglas T, Powell R, Savulescu J (2013) Is the creation of artificial life morally significant? Stud Hist Phil Biol Biomed Sci 44(4: Part B):688-696

58. Bacon F (1906) The advancement of learning and New Atlantis. Oxford University Press, Oxford

59. Link H-J (2013) Playing God and the intrinsic value of life: moral problems for synthetic biology? Sci Eng Ethics 19(2): 435-448

60. Hauskeller M (2011) Human enhancement and the giftedness of life. Philos Pap 40(1):55-79. https://doi.org/10.1080 /05568641.2011.560027

61. Jonas H (1974) Philosophical essays: from ancient creed to technological man. Atropos Press, New York

62. Schyfter P (2012) Standing reserves of function: a Heideggerian reading of synthetic biology. Philosophy \& Technology 25(2):199-219. https://doi.org/10.1007 /s13347-011-0053-4

63. Wordsworth W (2005) The tables turned. In: Ferguson M, Salter MJ, Stallworthy J (eds) The Norton anthology of poetry, 5th edn. W. W. Norton \& Co., New York, pp 764 765

Publisher's Note Springer Nature remains neutral with regard to jurisdictional claims in published maps and institutional affiliations. 